\title{
Ileocolonic ulcer treated by endoscopic application of collagen-polyvinylpyrrolidone
}

\author{
Andrés de Hoyos Garza MD¹, Edgar A Esparza Aguilar MD¹, Griselda Checa Richards MD²
}

\begin{abstract}
A de Hoyos Garza, EA Esparza Aguilar, G Checa Richards. Ileocolonic ulcer treated by endoscopic application of collagenpolyvinylpyrrolidone. Can J Gastroenterol 2007;21(8):513-515.

Ulceration is a complication that may occur after an ileocolonic anastomosis. Most of the etiologies remain speculative. The case of a 33-year-old woman with eosinophilic colitis is reported, in whom a colectomy with an ileocolonic anastomosis was performed. After four months, the patient presented with a stenosis in the ileocolonic anastomosis, necessitating surgical restoration. Four weeks later, the patient presented with rectal bleeding, and a colonoscopy showed an ulcer in the anastomosis. Collagenpolyvinylpyrrolidone was applied into and on the surface of the ulcer, and five days later the procedure was repeated. Follow-up endoscopies at seven days and three months showed complete healing of the ulcer and the patient remained without bleeding throughout a further four weeks of follow-up tests. It was concluded that this biological product could be an excellent treatment for these lesions.
\end{abstract}

\section{Un ulcère iléocolique traité par application endoscopique de collagène polyvinyle pyrolidone}

\begin{abstract}
Lulcération est une complication qui peut se produire après une anastomose iléocolique. La plupart des étiologies demeurent spéculatives. On présente le cas d'une femme de 33 ans atteinte de colite éosinophile dans le présent article, chez qui on a procédé à une colectomie avec anastomose iléocolique. Au bout de quatre mois, la patiente souffrait d'une sténose de l'anastomose iléocolique, exigeant une restauration chirurgicale. Quatre semaines plus tard, la patiente a consulté pour des saignements rectaux, et une coloscopie a révélé un ulcère de l'anastomose. On a appliqué du collagène polyvinyle pyrolidone à la surface de l'ulcère et dans celui-ci et on a repris l'intervention cinq jours plus tard. Des endoscopies de suivi au bout de sept jours et de trois mois ont révélé une cicatrisation complète de l'ulcère, et la patiente n'a présenté aucun saignement pendant les quatre autres semaines de tests de suivi. On a conclu que ce produit biologique peut constituer un excellent traitement pour ces lésions.
\end{abstract}

Key Words: Collagen-polyvinylpyrrolidone; Ileocolonic ulcer; Ulcer healing

Gew articles have been written that describe ulcers occurFring at colonic anastomotic sites. The most common clinical manifestations include pain, diarrhea and iron deficiency anemia along with evidence of gross or occult gastrointestinal blood loss. The time interval between surgery and detection of an anastomotic ulcer ranges from 15 months to 28 years (1). In most patients, ulcer etiology remains speculative but may include small bowel Crohn's disease and ingestion of nonsteroidal anti-inflammatory drugs.

In these cases, the most common therapeutic approach is to discontinue all nonsteroidal anti-inflammatory drugs or treat the underlying inflammatory bowel disease. Surgery should be reserved for life-threatening bleeds or for anemia refractory to oral iron therapy $(1,2)$.

While no effective local therapies for ileocolonic ulcers have yet been identified, we recently published a paper (3) that described the use of collagen-polyvinylpyrrolidone (collagen-PVP) for successful treatment of peptic ulcers. This relatively new biological agent, which is a mixture of native type I collagen and PVP, has been shown to improve the healing process. The present paper reports a patient suffering from an ileocolonic ulcer that was successfully treated with a
collagen-PVP injection into the ulcer. Colonoscopy revealed improvement in the ulcer in just 12 days.

\section{CASE PRESENTATION}

A 33-year-old woman was admitted to the hospital suffering from liquid diarrhea with five to 10 bowel movements per day and diffuse abdominal pain. After laboratory work-up, biopsy of the colon revealed more than 60 eosinophils per high-power field, which led to a diagnosis of eosinophilic colitis.

After several treatments with steroids and other immunosuppressors, the patient did not show any improvement, as evidenced by worsening diarrhea. Consequently, in an attempt to stop the persistent diarrhea and in the absence of other treatment options, a colectomy with an ileocolonic anastomosis was performed. Four months later, the patient complained of pain and rectal tenesmus and a diagnosis of incomplete obstruction by stenosis in the area of the ileocolonic anastomosis was made. Balloon dilation was not considered as a treatment option because the stenosis was too significant for the endoscope to pass easily through the lesion. As a result, it was necessary to restore the ileocolonic anastomosis. However, one

\footnotetext{
${ }^{1}$ Gastroenterology; ${ }^{2}$ Anesthesiology, Angeles del Pedregal Hospital, Mexico City, Mexico

Correspondence and reprints: Dr Andrés de Hoyos Garza, Hospital Angeles del Pedregal, Camino a Santa Teresa 1055-119, Héroes de Padierna,

Delegación Magdalena Contreras, 10700 Mexico City, Mexico. Telephone 55-5568-8946, fax 55-5568-8946, e-mail andehoyos@yahoo.com

Received for publication August 2, 2006. Accepted September 25, 2006
} 

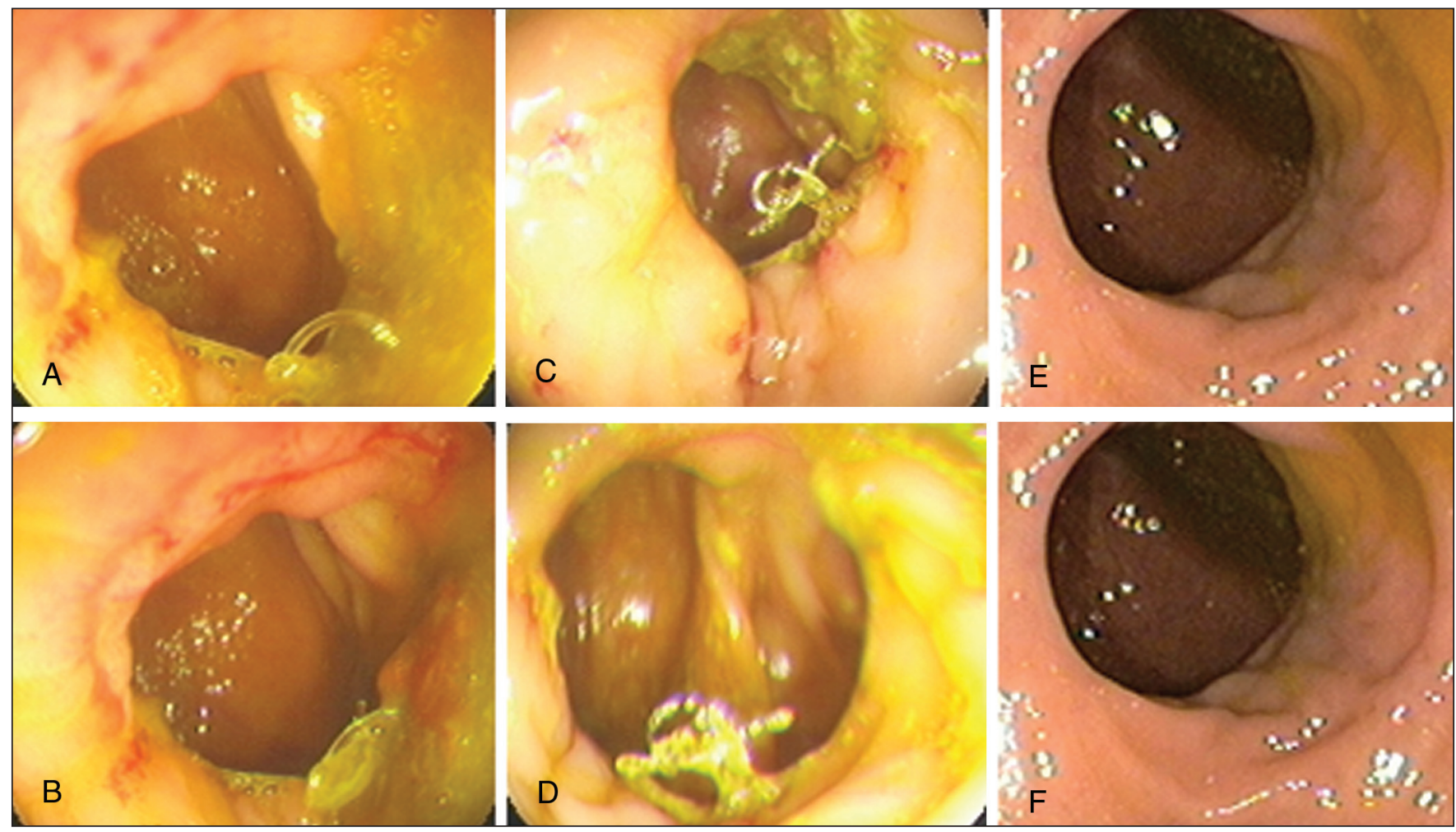

Figure 1) A and B Ulcer on the ileocolonic anastomosis. C and D Endoscopic appearance five days after a first application of collagenpolyvinylpyrrolidone. $\mathrm{E}$ and $\mathbf{F}$ Total healing three months after the second application of collagen-polyvinylpyrrolidone

month later, the patient presented with abdominal pain, tenesmus and rectal bleeding for a period of three days. A colonoscopy revealed an ulcer in the ileocolonic anastomosis $15 \mathrm{~cm}$ from the anal verge (Figures $1 \mathrm{~A}$ and $1 \mathrm{~B}$ ). The decision was made to administer $3 \mathrm{~mL}$ of collagen-PVP diluted in $3 \mathrm{~mL}$ of distilled water using a varices injector (Wilson-Cook Medical model TDVI-23 [Cook Group Inc, USA]), with a 7-Fr catheter and a 23-gauge needle. The amount of solution was chosen empirically and was injected only in and around the lesion and sprayed over the surface of the ulcer. This decision was supported by previous reports of cases in which collagenPVP treatment was successfully used (injecting intramuscularly and subcutaneously for patients with rheumatoid arthritis and scleroderma, and application to the surface of dermatological ulcers secondary to venous insufficiency [4-6], as well as in the case described in our previous publication [3]). The patient consented to the use of the biological compound for treatment. After five days, a significant improvement was observed (Figures 1C and 1D) and the same amount of collagen-PVP was once again injected. Endoscopies seven days and three months later showed the ulcer had completely healed (Figures $1 \mathrm{E}$ and $1 \mathrm{~F}$ ). Three months after the application of collagen-PVP, no bleeding and no side effects were observed.

\section{DISCUSSION}

We decided to use the collagen-PVP to treat the ileocolonic ulcer in our patient because this product had demonstrated its effectiveness in a previous case of a bleeding peptic ulcer in which the lesion showed significant healing $24 \mathrm{~h}$ after the application of collagen-PVP (3). This new biological product has been analyzed and has displayed many beneficial properties in improving the healing process in different studies $(3,7)$.
As previously reported, collagen-PVP is a biological agent derived from gamma irradiation of a mixture of type I pepsinized porcine collagen and PVP. This biopolymer has proven to modulate chronic inflammatory processes and improve skin wound repair and bone fractures in rats. It also modulates collagen turnover by decreasing collagenolytic activity and tissue inhibitor of metalloproteinase- 1 production and increasing the amount of type III collagen. This is possibly accomplished by downregulating proinflamamatory cytokines and adhesion molecules such as intercellular adhesion molecule-1, vascular cell adhesion molecule-1, interleukin-1beta, tumour necrosis factor-alpha and platelet-derived growth factor $(3,7-10)$. Intralesional injection of collagen-PVP once a week for one to three months into human hypertrophic scars or scleroderma lesions diminishes pruritus, pain, erythema, volume and inflammatory infiltrates $(5,11)$. This product makes tissue architecture resemble normal skin and modifies the histological and biochemical pattern of fibrosis without changing the total collagen content (12). Subcutaneous or intramuscular administration of collagen-PVP to rheumatoid arthritis patients has proven to be a safe and well-tolerated drug for short-term treatments. It has induced a statistically significant improvement in basal versus three or six months of treatment in cases of morning stiffness, as assessed by the Ritchie Index, swollen joint count, Disease Activity Score, Visual Analogue Scale, Health Assessment Questionnaire-Disability Index and the American College of Rheumatology 20/50/70 scales $(4,13)$. Collagen-PVP has also been used in plastic surgery, where it has been beneficial in the healing of ulcers due to venous insufficiency (6).

Based on the experience of the patient discussed in the present paper, collagen-PVP once again demonstrated its 
efficacy for healing ulcer lesions, probably by means of the many processes that regulate collagen metabolism. Collagen-PVP also has the advantage of being a biological drug with minimal risks, given that no side effects have been found in healthy volunteers and patients treated for hypertrophic scars over long periods of time (14). This endoscopic ulcer treatment should be considered as an option in all cases that have not met with successful results using conventional treatments.

ACKNOWLEDGEMENT: The authors thank Dr Janette Furuzawa for her generous review on this work.

\section{REFERENCES}

1. Sondheimer JM, Sokol RJ, Narkewicz MR, Tyson RW. Anastomotic ulceration: A late complication of ileocolonic anastomosis. J Pediatr 1995;127:225-30.

2. Chari ST, Keate RF. Ileocolonic anastomotic ulcers: A case series and review of the literature. Am J Gastroenterol 2000;95:1239-43.

3. de Hoyos A, Monroy MA, Checa G, Rodríguez P.

Collagen/povidone as a new endoscopic treatment option in peptic ulcer bleeding. Endoscopy 2006;38:99.

4. Furuzawa-Carballeda J, Fenutria-Ausmequet R, Gil-Espinosa V, et al. Polymerized-type I collagen for the treatment of patients with rheumatoid arthritis: Effect of intramuscular administration in a double blind placebo-controlled clinical trial. Clin Exp Rheumatol 2006;24:514-20.

5. Furuzawa-Carballeda J, Krötzch E, Barile-Fabris L, Alcalá M, Espinoza-Morales R. Subcutaneous administration of collagenpolyvinylpyrrolidone down-regulates IL- $1 \beta$, TGF- $\beta 1$, ELAM-1 and VCAM-1 expression in scleroderma skin lesions. Clin Exp Dermatol 2005;30:83-6.
6. Suàrez CA, Salgado RM, Apis HAMZ, Krotzsch E. Inducción del tejido de granulación por pasta de Lassar vs colágena-

polivinilpirrolidona en úlceras por insuficiencia venosa. Cir Plast 2004;14:5-13.

7. Krôtzsch GF, Guerrero-Padilla E, Díaz de León L. Morphological studies on the effects of fibroquel during wound healing of surgical wounds in rats. J Cell Biochem 1993;17E(Suppl):R506.

8. Krotzsch GF, Diaz de Leòn L. Effect of fibroquel on collagen metabolism in cellular cultures. The Wound Healing Society: Fifth Annual Scientific Meeting. Minneapolis, April 27 to 30, 1995.

9. Furuzawa-Carballeda J, Alcocer-Varela J, Krotzsch-Gomez FE, Díaz de León L. La colágena-polivinilpirrolidona regula la expresión de moléculas de adhesión y la actividad colagenolitica en cultivos sinoviales de pacientes con artritis reumatoide. Rev Mex Rehumatol 1999 Vol. 14 XXVII congreso mexicano de rehumatologia febrero 12-16 1999.

10. Furuzawa-Carballeda J, Alcocer-Varela J, Díaz de León L. CollagenPVP decreases collagen turnover in synovial tissue cultures from rheumatoid arthritis patients. Ann N Y Acad Sci. 1999;878:598-602.

11. Krötzsch-Gómez FE, Furuzawa-Carballeda J, Reyes-Márquez R, Quiroz-Hernandez E, Diaz de Leon L. Cytokine expression is downregulated by collagen-polyvinylpyrrolidone in hypertrophic scars. J Invest Dermatol 1998;111:828-34.

12. Furuzawa-Carballeda J, Rodriguez-Caldeon R, Díaz de León L, Alcocer-Varela J. Mediators of inflammation are down-regulated while apoptosis is up-regulated in rheumatoid arthritis synovial tissue by polymerized collagen. Clin Exp Immunol 2002;130:140-9. (Erratum in 2002;130:565-6).

13. Furuzawa-Carballeda J, Cabral AR, Zapata-Zúñiga M, AlcocerVarela J. Subcutaneous administration of polymerized-type I collagen for the treatment of patients with rheumatoid arthritis: An open-label pilot trial. J Rheumatol 2003;30:256-9.

14. Furuzawa-Carballeda J, Rojas E, Valverde M, Castillo I, Díaz de León L, Krötzsch E. Cellular and humoral responses to collagenpolyvinylpyrrolidone administered during short and long periods in humans. Can J Physiol Pharmacol 2003;81:1029-35. 


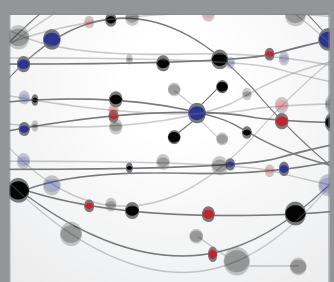

The Scientific World Journal
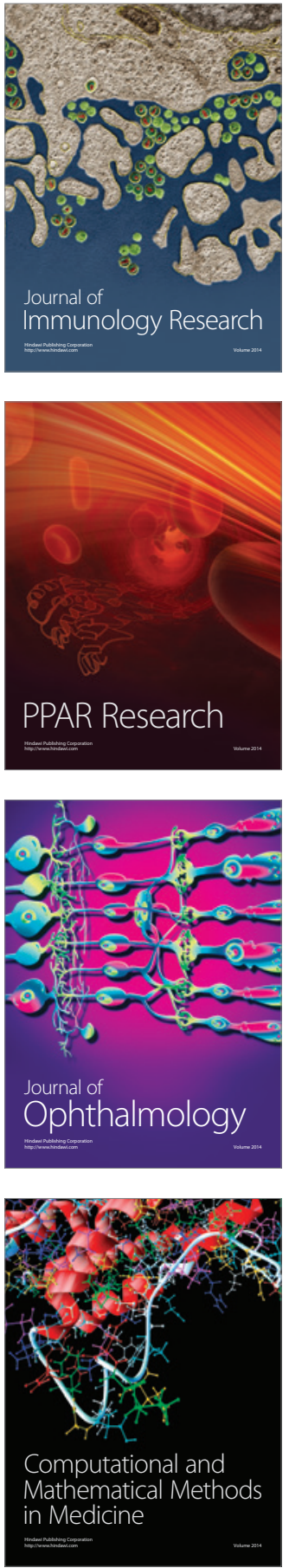

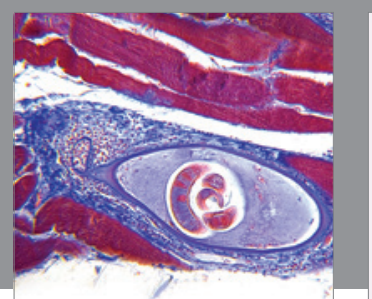

Gastroenterology Research and Practice

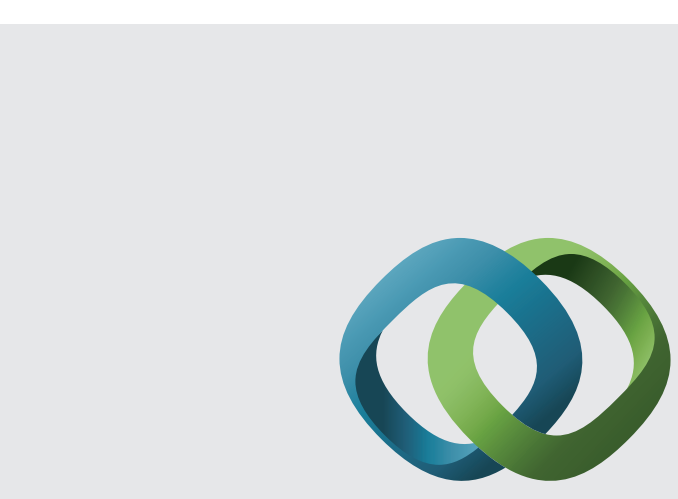

\section{Hindawi}

Submit your manuscripts at

http://www.hindawi.com
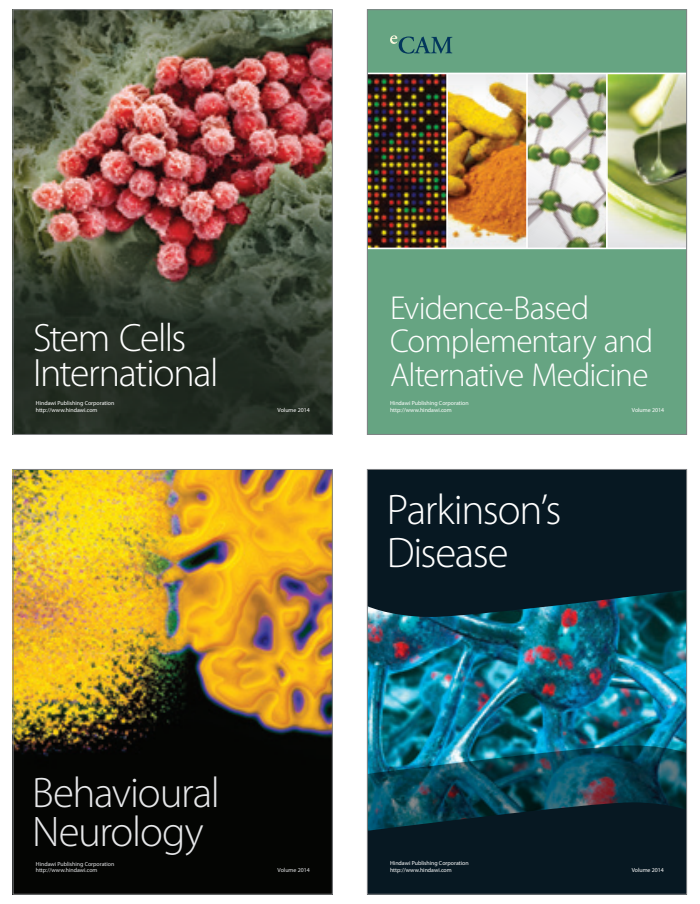
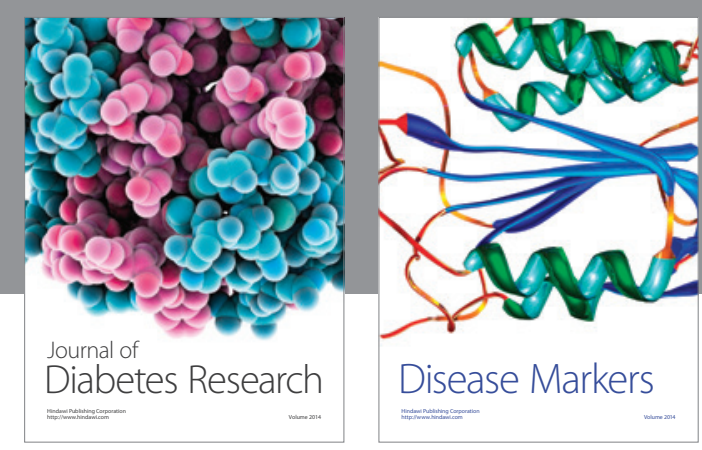

Disease Markers
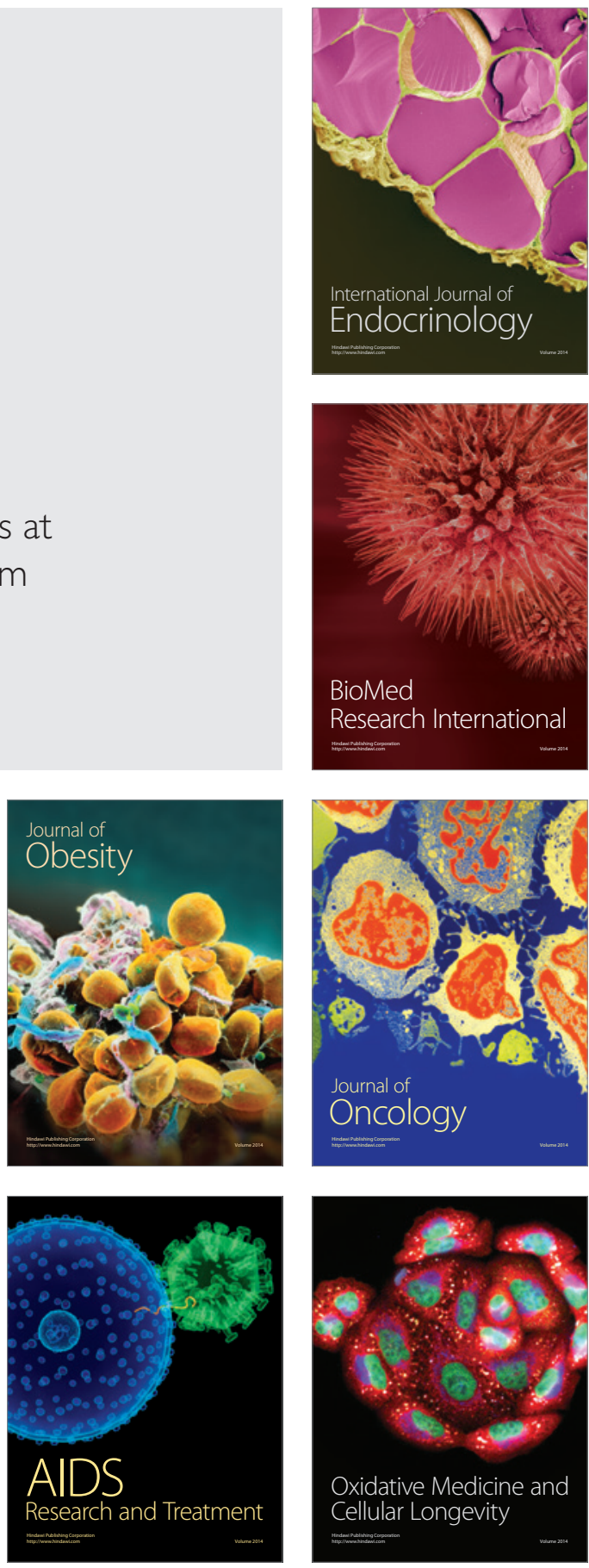